\title{
CONDIÇÕES FACILITADORAS E ASPECTOS LIMITADORES AO PROCESSO DE IMPLANTAÇÃO DA EMPRESA ZPE CEARÁ À LUZ DA VISÃO BASEADA NAS INSTITUIÇÕES
}

\section{FACILITATIVE CONDITIONS AND LIMITING ASPECTS FOR THE PROCESS OF IMPLANTATION OF THE ZPE CEARÁ COMPANY UNDER THE PERSPECTIVE OF THE INSTITUTION-BASED VIEW}

\section{Paulo Roberto de Carvalho Nunes}

Doutorando em Administração de Empresas e professor assistente da Universidade de Fortaleza (Unifor).

\section{Maria Salvelina Marques Lourenço}

Doutoranda do Programa de Pós-Graduação em Administração de Empresas da Universidade de Fortaleza (Unifor) e professora assistente IV da Universidade Federal do Ceará (UFC).

\section{José Milton de Sousa Filho}

Doutor em Administração de Empresas pela Fundação Getulio Vargas-SP (FGV-EAESP).

Professor Adjunto da Universidade de Fortaleza (UNIFOR), vinculado ao Programa de

Pós-Graduação em Administração de Empresas (PPGA).

\section{RESUMO}

Os países emergentes têm adotado políticas públicas de comércio exterior que priorizam estratégias de internacionalização de negócios, como as Zonas de Processamento de Exportação (ZPE). No Brasil, a empresa ZPE CEARÁ foi constituída pelo estado do Ceará com a missão de implantar a ZPE do Pecém, a primeira dessas áreas a operar. Esta pesquisa objetiva identificar e caracterizar as condições facilitadoras e os aspectos limitadores do processo de implantação da empresa ZPE CEARÁ, à luz da Visão Baseada nas Instituições, concluindo que fatores relacionados a essa teoria influenciaram o processo de implantação da empresa, especialmente quanto às condições facilitadoras.

Palavras-chave: Visão Baseada nas Instituições; políticas públicas de comércio exterior; ZPE CEARÁ.

\section{ABSTRACT}

Emerging countries have adopted public policies of foreign trade that prioritize trade strategies of business internationalization such as Zonas de Processamento de Exportação (ZPE) [Export Processing Zones]. In Brazil, the company ZPE CEARÁ was established by the state of Ceará with a mission to deploy the ZPE do Pecém, the first of these areas to operate. This research aims to identify and characterize the facilitative conditions and limiting aspects of the implementation process of the company ZPE CEARÁ under the perspective of the Institution-Based View, concluding that factors related to this theory influenced the deployment process of the company, especially regarding facilitative conditions.

Keywords: Institution-Based View; policies on foreign trade; ZPE CEARÁ. 


\section{INTRODUÇÃO}

O que tradicionalmente orienta a estratégia empresarial em negócios internacionais, determinando o sucesso e o fracasso de empresas ao redor do mundo, são as teorias que consideram a Visão Baseada em Recursos (Resource-Based View - RBV) e a Visão Baseada na Indústria (Industry-Based View - IBV) (PENG, 2008).

Críticas recentes indicam que essas visões ignoram a base institucional que fornece o contexto da concorrência entre as empresas. Pesquisadores demonstram, cada vez mais, que em economias emergentes, cujas instituições diferem significativamente das economias desenvolvidas, há crescente reconhecimento de que as instituições moldam de forma relevante a estratégia e o desempenho das empresas (Ibidem).

Leung et al. (2005) e Redding (2005) argumentam de forma convincente que a pesquisa em negócios internacionais deve se concentrar mais no contexto das instituições, motivo pelo qual defendem o surgimento de uma Visão Baseada em Instituições (Institution-Based View) para estratégias em negócios internacionais.

Nesse contexto, observa-se que os países emergentes têm definido e implementado políticas públicas de comércio exterior que formalizam certas condições especiais para a viabilização de estratégias de internacionalização de seus negócios.

Segundo o Ministério do Desenvolvimento, Indústria e Comércio Exterior (MDIC), a experiência internacional demonstra que essas políticas são essenciais e que instrumentos como as denominadas Zonas de Processamento de Exportação (ZPE) permitiram resultados importantes para países emergentes como a China que, por meio de suas ZPE e regimes congêneres, alcançou um significativo incremento nas suas exportações no período de 1980 a 2010, passando de US\$ 18 bilhões para US\$ 1,578 bilhão (MDIC, 2013a, 2013b).
No Brasil, as ZPE se caracterizam como áreas de livre comércio com o exterior, destinadas à instalação de empresas voltadas para a produção de bens a serem comercializados internacionalmente, sendo consideradas zonas primárias para efeito de controle aduaneiro (Lei no 11.508/2007, art. $1^{\circ}$, § único).

Atualmente, o Brasil conta com $24 \mathrm{ZPE}$, entre as quais se destacam, por seu estágio avançado de implantação, as localizadas nos estados do Acre, Piauí e Ceará. A ZPE do Ceará está sediada no município de São Gonçalo do Amarante, nas proximidades do Porto do Pecém, ocupando uma área de $4.271,41$ ha, enquanto as outras duas contam com 130,17 ha e 348,80 ha, respectivamente. Possui dois projetos já aprovados, ambos em fase de implantação (MDIC, 2013a, 2013b).

Ao revisar a literatura sobre o tema, observouse uma carência de estudos sobre a implantação das ZPE no Brasil, especialmente sobre sua relação com a Visão Baseada nas Instituições enquanto instrumentos de políticas públicas de comércio exterior, que formalizam condições especiais para viabilização de estratégias de internacionalização das empresas brasileiras.

Diante do exposto, o problema para esta pesquisa é: Como se deu o processo de implantação da empresa ZPE CEARÁ enquanto agente institucional para implementação de políticas públicas de comércio exterior?

Estando relacionado ao problema referido, o objetivo geral desta pesquisa é identificar e caracterizar as condições facilitadoras e os aspectos limitadores do processo de implantação da empresa ZPE CEARÁ, à luz da Visão Baseada nas Instituições.

A revisão teórica apresentará definições e conceitos sobre estratégias de internacionalização de negócios a partir da Visão Baseada nas Instituições destacando-se os aspectos formais, especialmente os relativos à inserção de empresas de países emergentes em mercados internacionais.

Tratará ainda da importância e responsabilidade por parte dos que fazem a gestão pública 
quanto à definição e implementação de políticas públicas voltadas para o comércio exterior, formalizando condições especiais para viabilização de estratégias de internacionalização das empresas.

Do ponto de vista metodológico, a pesquisa se classifica como qualitativa, exploratória, descritiva, bibliográfica, de campo, documental e estudo de caso. Os dados foram coletados por meio da realização de entrevistas e análise de documentos acerca do processo de implantação da empresa ZPE CEARÁ, responsável pela gestão da área de livre comércio com o exterior e destinada à instalação de empresas voltadas para a produção de bens a serem comercializados no exterior, no estado do Ceará.

Este trabalho está estruturado nas seguintes seções, além desta introdução: A seção 2 trata da fundamentação teórica que embasa este estudo; a seção 3 mostra a metodologia aplicada a esta pesquisa, indicando os meios de obtenção dos dados e os critérios de análise; a seção 4 apresenta e discute os resultados; a seção 5 mostra as conclusões deste estudo, apresenta suas limitações e recomenda a realização de novos estudos e, finalmente, a seção 6 trata dos agradecimentos.

\section{REFERENCIAL TEÓRICO}

Esta seção trata da Visão Baseada nas Instituições, como abordagem para definir estratégias para a internacionalização de negócios. Trata também sobre políticas públicas de comércio exterior, sendo viabilizadora de estratégias de internacionalização de negócios em mercados emergentes.

\subsection{Visão Baseada nas Instituições e a definição de estratégias para internacionalização de negócios}

As estratégias para a internacionalização de negócios, tradicionalmente, orientam-se pela IBV e pela RBV. Já a Visão Baseada em Instituições geralmente é tratada como questão de segundo plano (PENG; WANG; JIANG, 2008).

Peng, Wang e Jiang (2008) entendem que as condições da indústria (IBV) e os recursos e capacidades da empresa (RBV) não são suficientes para orientar as estratégias de internacionalização dos negócios. Argumentam que a expansão internacional deve levar em consideração a base institucional que fornece o contexto de concorrência entre as organizações. Assim, defendem que as estratégias de internacionalização devem ser orientadas por três visões (teorias), que constituem o "tripé estratégico": a IBV, a RBV e a Visão Baseada em Instituição. Os autores alegam que essas três teorias, se utilizadas conjuntamente, além de ajudar a sustentar o tripé estratégico, também podem contribuir com o entendimento de questões fundamentais referentes à orientação da estratégia de internacionalização e aos determinantes do sucesso e do fracasso das empresas. Os autores também afirmam que, em economias emergentes, cujas instituições diferem das economias desenvolvidas, há um crescente reconhecimento de que as instituições moldam significativamente a estratégia e o desempenho das empresas. Afirmam também que a pesquisa sobre as economias emergentes impulsionou a Visão Baseada em Instituições para a vanguarda da pesquisa em estratégia. Ressaltam que uma estratégia apoiada na Visão Baseada em Instituições centra-se na interação dinâmica entre instituições e organizações, e consideram as escolhas estratégicas como o resultado de cada uma das interações.

As instituições são definidas por North (1990) como restrições formais e informais que estruturam as interações humanas, sendo consideradas as regras do jogo que impõem constrangimentos aos jogadores (indivíduos e organizações) em suas interações. Scott (2008), por sua vez, define instituições como estruturas e atividades regulativas, normativas e cognitivas que conferem estabilidade e significado à conduta social. 
Observa-se que North (1990) deu ênfase aos aspectos regulatórios do ambiente institucional, enquanto Scott (2008) considerou, além dos aspectos regulatórios, os cognitivos e os normativos. O pilar regulatório constitui o "poder coercitivo dos governos" e se expressa por meio das instituições formais, como as leis e os regulamentos. Os pilares cognitivo e normativo abarcam as instituições informais, alicerçadas na cultura. O cognitivo "refere-se aos valores e crenças, internalizados e convencionados, que dirigem o comportamento dos indivíduos e das empresas". O normativo, por sua vez, "refere-se a como valores, crenças e normas de jogadores relevantes influenciam o comportamento dos indivíduos e das empresas" (PENG, 2008, p. 96).

As instituições influenciam o processo de tomada de decisões, indicando quais são as condutas aceitáveis e quais as que não são. Ao referir-se à maneira de gerenciar as empresas na China, Peng (2010, p. 8) destaca a "necessidade de sempre estar atento ao que o governo faz, ao que o governo diz, às decisões que o governo toma e ao que o governo quer", e acrescenta que "há completa clareza de que o governo é o patrão e ele precisa ser obedecido. É imprescindível jogar de acordo com essas regras."

Segundo a Câmara de Comércio Exterior (CAMEX, 2009), a interação entre governo e empresa pode solucionar questões importantes referentes à busca do desenvolvimento econômico e da expansão internacional. Entretanto, essa instituição informa que há muitas teorias e argumentos a favor e contra essa estratégia e destaca que o papel dos governos no processo de internacionalização varia bastante, especialmente em relação ao grau de intervenção do Estado na economia.

Peng (2008) destaca que a principal função das instituições é a redução da incerteza, o que considera relevante em virtude das consequências adversas que dela poderão advir, que são a possibilidade da incerteza política tornar obsoletos os planejamentos de longo prazo e a incerteza econômica que pode resultar em perdas econômicas decorrentes dos custos de transação. Assim, "administradores e empresas buscam racionalmente seus interesses e fazem escolhas estratégicas dentro de restrições institucionais" (Ibidem, p. 102), formais e informais. O autor alega que, quando as instituições formais falham, as informais exercem o relevante papel de reduzir a incerteza e dar estabilidade aos negócios.

\subsection{Políticas públicas de comércio exterior e a definição de estratégias de internacionalização de negócios em mercados emergentes}

As estratégias de internacionalização das empresas são afetadas tanto pelas políticas públicas de seus países de origem quanto pela estrutura legal que disciplina os fluxos de capitais em nível global. Segundo Acioly e Schatzmann (2009), as políticas públicas influenciam o volume, a natureza e os motivos dos investimentos diretos no exterior (IDE) de tal forma que o padrão desses investimentos reflete o contexto institucional e político sobre o qual as estratégias de internacionalização das empresas se desenvolvem. Os autores citam como exemplos de políticas públicas de promoção e apoio à internacionalização: (i) o apoio informacional, assistência técnica e outras orientações; (ii) a criação, no país de destino do investimento, de um comfort zone (caso China-Singapura, com o Park Industrial de Suzhou); (iii) a concessão de incentivos fiscais e tributários, reduzindo os custos dos projetos de investimentos; (iv) a concessão de garantias para minimização de riscos, inclusive o político; (v) a disponibilização de linhas de financiamentos específicas; (vi) a celebração de acordos internacionais.

Segundo a CAMEX (2009), a internacionalização de empresas oriundas de países emergentes constitui um fenômeno recente, que ocorreu de maneira mais intensa a partir da década de 1980, 
com destaque para os Tigres Asiáticos, a China e a Índia. Os Tigres Asiáticos estão entre os casos mais bem sucedidos de desenvolvimento econômico do século passado, tendo alcançado um alto nível de industrialização, com alta qualidade de vida e intensa atuação no comércio internacional - especialmente devido à parceria entre governos e setor privado - de forma articulada, integrada, com visão de longo prazo e autonomia quanto às pressões setoriais e de grupos de interesse (Ibidem).

A China iniciou seu processo de internacionalização em 1970, quando o país inaugurou um conjunto de reformas econômicas que visavam a atrair investimentos estrangeiros para as zonas econômicas especiais e estimular a iniciativa privada chinesa a buscar as exportações. Entretanto, a consolidação da internacionalização chinesa só começou em 1990. Entre 1990 e 2007, os investimentos diretos da China no mundo cresceram quase 30 vezes, passando de US\$ 830 milhões em 1990 para US\$ 22,5 bilhões em 2007. Esse crescimento tornou-se mais intenso após 2002, em decorrência de novas medidas de apoio à internacionalização (ACIOLY; ALVES; LEÃO, 2009).

Em 2002, o governo chinês instituiu a GOGlobal, política pública destinada a incentivar a internacionalização das empresas chinesas, onde se destacam as medidas de: simplificação de procedimentos para o exame e aprovação dos projetos de investimento; elaboração de guias para investidores; realização de atividades de inteligência comercial; assinatura de acordos internacionais de promoção e proteção de investimentos; criação do Fundo Soberano Chinês e extinção da obrigatoriedade de enviar à China os lucros auferidos no exterior (CAMEX, 2009, p. 16). Em relação à eficácia dessas medidas, Acioly, Alves e Leão (2009) argumentam que as teorias clássicas de internacionalização dos negócios não explicam plenamente esse processo na China, que foi fortemente comandado pelo Estado a partir de mudanças políticas e institucionais.
Já a internacionalização das empresas indianas, inicialmente, foi liderada pela iniciativa privada, especialmente por empresas de prestação de serviços de tecnologia da informação. O governo indiano era muito criticado pelos empresários do país, que se queixavam da baixa qualidade da infraestrutura e das normas consideradas burocráticas, confusas e excessivas (CAMEX, 2009).

Em 1991, após a crise do balanço de pagamentos, o governo indiano adotou uma série de medidas ligadas principalmente à diminuição de restrições de investimentos feitos por empresas indianas no exterior. Entretanto, a progressiva liberalização desses investimentos só foi possível após o ano 2000, em decorrência do acúmulo de reservas internacionais (Ibidem).

Diante do exposto, percebe-se que o Estado, por meio de seus agentes governamentais, institui e implementa políticas públicas que incentivam e favorecem o processo de internacionalização empresarial, eliminando barreiras em suas estruturas regulatórias e criando condições necessárias à expansão internacional das empresas. Por esse motivo, considerando o objetivo deste trabalho, discorre-se a seguir sobre as definições referentes a uma dessas políticas públicas, as ZPE.

\subsubsection{Zonas de Processamento de Exportação (ZPE)}

Dados da Organização Internacional do Trabalho (OIT) apresentados pela Associação Brasileira de Zonas de Processamento de Exportação (ABRAZPE, 2010) revelam que, entre as estratégias de internacionalização utilizadas pelos Tigres Asiáticos, no caso a China e a Índia, destacam-se as ZPE como responsáveis pelo acelerado crescimento desses países.

Nesse sentido, um estudo de Santos Junior (2013) indica que a estratégia de utilização das ZPE como meio para combinar investimento estrangeiro direto e comércio exterior tem se caracterizado 
como a mais bem sucedida, sendo uma das responsáveis pelo grande crescimento econômico experimentado na China, país onde esse modelo mais prosperou. Isso pode ser evidenciado, por exemplo, pela evolução de $2.700 \%$ da economia de Shenzen desde 1979, a partir do estabelecimento de sua Special Economic Zone (SEZ). O autor argumenta que as ZPE constituem "um tipo de regime aduaneiro em áreas de fabricação cuja produção é destinada integralmente ao exterior." Entretanto, alguns países são flexíveis, permitindo que parte da produção seja comercializada no próprio país. Nesse caso, a produção comercializada internamente não conta com os benefícios inerentes à exportação. O autor destaca o papel fundamental das ZPE quanto a:

(i) criar um ambiente propício para promover investimentos e informações; (ii) fomentar uma mudança tal que empresários nacionais se interessem pela atividade exportadora; e (iii) oferecer condições mais favoráveis e menos burocráticas para a instalação de projetos industriais (SANTOS JUNIOR, 2013, p. 53).

Assim, uma "boa política" de instituição de ZPE deve atender aos seguintes objetivos: "(i) gerar empregos locais, (ii) promover a melhoria contínua das competências profissionais locais, (iii) difundir novas tecnologias, (iv) fomentar a inovação, (v) não se limitar ao processamento de insumos estrangeiros"(Ibidem, p. 52).

Por outro lado, as opiniões sobre as ZPE são divergentes. Delfim Neto e Braga (2006) informam que os críticos dessa modalidade de apoio à internacionalização apontam algumas desvantagens, como perda da receita fiscal, concorrência desleal com as demais empresas instaladas no país, incompatibilidade com as regras da Organização Mundial do Comércio (OMC) e do Mercado Comum do Sul (MERCOSUL), entre outras. Entretanto, os autores alegam que esses argumentos são equivocados e inconsistentes.
DeacordocomoMinistério deDesenvolvimento, Indústria e Comércio Exterior (MDIC), as ZPE são caracterizadas como áreas de livre comércio com outros países destinadas à instalação de empresas voltadas para a produção de bens a serem comercializados no exterior. Além disso, as empresas que se instalam em ZPE têm acesso a tratamentos tributários, cambiais e administrativos específicos, sendo seu principal requisito o caráter eminentemente exportador, motivo pelo qual as empresas devem auferir e manter a receita bruta decorrente de exportações de, no mínimo, 80\% de sua receita bruta total (MDIC, 2013b).

Nesse contexto, o MDIC (2013b) registra que as principais finalidades das ZPE são: atrair investimentos estrangeiros; reduzir desequilíbrios regionais; fortalecer o Balanço de Pagamentos; promover a difusão tecnológica; criar empregos; promover o desenvolvimento econômico e social do país; e aumentar a competitividade das exportações brasileiras.

Originariamente, no Brasil, o regime aduaneiro especial das ZPE foi instituído pelo Decreto-Lei $n^{\circ} 2.452$, de 29 de julho de 1988, que autorizou, ao Poder Executivo, a criação de ZPE, por meio de edição de decreto presidencial. Para traçar a orientação da política da ZPE, estabelecer requisitos e analisar propostas, entre outras atividades, o normativo criou o Conselho Nacional das Zonas de Processamento de Exportação (CZPE) (MDIC, 2013b).

Posteriormente, em 2007, o Decreto-Lei $n^{\circ}$ 2.452/1988 foi revogado pela Lei $n^{\circ} 11.508 / 2007$, que manteve a competência do Conselho para definir as normas, os procedimentos e os parâmetros do programa, segundo os quais os agentes envolvidos devem balizar suas ações. Para regulamentar a Lei $n^{\circ} 11.508 / 2007$, foram publicados os Decretos $n^{\circ}$ 6.634/2008, que dispõe sobre o Conselho Nacional das ZPE (CZPE), e n 6.814/2009, que dispõe sobre o regime tributário, cambial e administrativo das ZPE (Ibidem). 
Nesse contexto, registra-se que existem no Brasil 24 ZPE em distintas fases pré-operacionais, dentre as quais está incluída a localizada em Pecém, no Ceará (Ibidem). A referida ZPE foi proposta pelo Governo do Estado do Ceará e autorizada pela Resolução CZPE n 03, de 26 de maio de 2010, bem como pelo Decreto de 17 de junho de 2010, sendo administrada pela empresa ZPE CEARÁ e ocupando uma área de 4.271,41 ha, a maior de todas as ZPE até agora autorizadas (Idem, 2013a).

\section{METODOLOGIA}

A pesquisa se classifica como qualitativa, pois a questão para a qual se busca resposta está associada a um fenômeno social cujo significado e relações entre variáveis envolvidas e características essenciais precisam ser conhecidos (BEUREN, 2004).

Quanto aos objetivos, entende-se que a tipologia da pesquisa se classifica como exploratória e descritiva, pois aborda temas ainda não muito tratados pela literatura referente à temática, além de buscar descrever, relatar e comparar os aspectos que contribuem para o alcance do objetivo da pesquisa, sem manipulação dos fenômenos (Ibidem).

Sobre a forma de condução e obtenção dos dados, a pesquisa é entendida como bibliográfica, pois busca conhecer as produções teóricas, a legislação, as normas técnicas, os estudos e outros meios documentais de transmissão de conhecimentos sobre as condições facilitadoras e os aspectos limitadores do processo de implantação da empresa ZPE CEARÁ, à luz da Visão Baseada nas Instituições, publicados sob a forma de livros, artigos, manuais e informações disponíveis em sites da internet (Ibidem).

Ainda em relação à obtenção dos dados, esta pesquisa é entendida como de campo, pois abrange levantamentos de dados sobre as condições facilitadoras e os aspectos limitadores do processo de implantação da empresa ZPE CEARÁ, à luz da Visão Baseada nas Instituições (VERGARA, 1997).
A pesquisa de campo foi realizada por meio de levantamento documental, tendo sido analisados os documentos denominados "Relatório de Desempenho da Gestão" da Empresa Administradora da Zona de Processamento de Exportação de Pecém S/A (EMAZP), primeira denominação da empresa ZPE CEARÁ, relativos aos anos de 2010, 2011 e 2012.

A coleta de dados foi efetuada também por meio de entrevistas com três executivos da gestão superior da empresa ZPE CEARÁ, sendo que dois deles já se encontravam afastados dos respectivos cargos quando foram indagados acerca das condições facilitadoras e dos aspectos limitadores do processo de implantação da companhia para esta pesquisa.

Quanto à estratégia de pesquisa, este trabalho classifica-se como um estudo de caso. De acordo com Yin (2005, p. 32), estudo de caso é uma pesquisa empírica que "investiga um fenômeno contemporâneo dentro do seu contexto de vida real, especialmente quando os limites entre o fenômeno e o contexto não estão claramente definidos."

Após a coleta de dados inicia-se o processo de classificação. De acordo com Rudio (1995), a classificação é uma forma de discriminar e selecionar as informações obtidas, a fim de reuni-las em grupo de acordo com o interesse do pesquisador.

\section{ANÁLISE E DISCUSSÃO}

Nesta seção são apresentadas análises dos documentos pesquisados relacionados ao processo de implantação da empresa ZPE CEARÁ e sínteses qualitativas das respostas das pessoas entrevistadas quanto à identificação e caracterização das condições facilitadoras e dos aspectos limitadores do processo de implantação da empresa ZPE CEARÁ.

\subsection{Análise documental}

De acordo com o Relatório de Desempenho de Gestão de 2010, apresentado pela EMAZP 
(2011, p. 1), "o Ceará vem se consolidando, nos últimos anos, como um dos estados brasileiros bem sucedidos em atrair investimentos, especialmente os voltados para exportação de produtos manufaturados".

A implantação do Complexo Industrial e Portuário do Pecém, incluindo o Porto e a Zona de Processamento de Exportação (ZPE do Pecém), constitui-se em estratégia de desenvolvimento que possibilita a promoção de atividades industriais integradas que viabilizam a irradiação do desenvolvimento, da geração de emprego e renda e a integração regional (Ibidem).

Nesse contexto, o Governo Federal autorizou a criação da ZPE do Pecém, por meio do Decreto Federal de 16 de junho de 2010 (BRASIL, 2010). De acordo com a EMAZP (2011), a ZPE do Pecém contará com uma estrutura de beneficiamento e transformação industrial das matérias primas regionais, possibilitando um aumento significativo do valor agregado das exportações e a consequente elevação da capacidade de geração de empregos e de renda na região.

Para administrar a ZPE do Pecém, o Ceará constituiu, por meio da Lei Estadual no 14.794/2010, a EMAZP sob a forma de uma sociedade de economia mista vinculada ao Conselho Estadual de Desenvolvimento Econômico (CEDE), cuja Assembleia de Constituição ocorreu no dia 8 de dezembro de 2010 (EMAZP, 2011).

A missão da EMAZP é a "implantação de uma ZPE moderna e eficiente, fomentando o crescimento econômico, através do aumentando (sic) da competitividade exportadora do Estado, gerando emprego, renda e qualidade de vida" (Ibidem). Sua finalidade é gerenciar a implantação, operação e desenvolvimento da ZPE do Pecém de acordo com as normas pertinentes, especialmente as resoluções editadas pelo CZPE.

De acordo com o Relatório EMAZP (2011), a empresa encaminhou ainda em 2010 a solicitação de alfandegamento da ZPE do Pecém à Receita
Federal do Brasil (RFB), cumprindo assim, dentro do prazo estabelecido, a obrigação prevista legalmente quanto a esse mister.

O primeiro projeto analisado pela EMAZP foi o da Companhia Siderúrgica do Pecém (CSP), que estimava uma produção de três milhões de toneladas de aço por ano, com elevação posterior para seis milhões de toneladas. O investimento estava orçado em US\$ 4,69 bilhões de dólares e apresentava um potencial de geração de emprego na ordem de 4.000 durante a operação e 15.000 no pico da construção civil. Esse projeto foi posteriormente encaminhado ao CCZPE, onde foi aprovado em setembro de 2011, vindo a se constituir no primeiro projeto industrial aprovado para implantação em ZPE (Idem, 2012).

O Relatório EMAZP (2012) informa que durante o ano de 2011 foram empreendidos esforços para o fornecimento de documentos e informações necessárias para a obtenção do alfandegamento para a área da ZPE do Pecém pela RFB, e que também foram encaminhadas articulações de divulgação e difusão sobre os benefícios do regime de ZPE junto à Federação das Indústrias do Estado do Ceará (FIEC) e sobre o estreitamento de laços com a Secretaria Especial do CZPE.

Durante o ano de 2012, registra o Relatório EMAZP (2013), intensificou-se o processo de consolidação da ZPE do Pecém e da EMAZP, sendo que essa empresa, junto da CSP, desenvolveu o projeto executivo para contratação dos sistemas operacionais necessários para o funcionamento e alfandegamento, tais como: sistema de controle aduaneiro, sistema de vigilância e monitoramento, sistema de controle de acesso e sistema de ativos de Tecnologia da Informação. A EMAZP protocolou o correspondente requerimento de criação, apresentando toda a documentação exigida pela RFB (Idem, 2013).

De acordo com o Relatório EMAZP (2013, p. 1), "a fase das obras de terraplanagem e obras estruturais realizadas pela CSP, iniciadas em junho 
de 2012, possibilitaram que, simultaneamente, pudessem ser contratados a instalação dos equipamentos e os sistemas de monitoramento para o processo de alfandegamento".

Posteriormente, em novembro de 2012, o CZPE concedeu a autorização para a instalação da segunda empresa na ZPE do Pecém, a Vale Pecém, subsidiária da empresa Vale do Rio Doce, que terá como propósito o fornecimento de minério para a CSP (Ibidem).

Além disso, de acordo com o Relatório EMAZP (2013), em dezembro de 2012 foi iniciada a mudança de nome da empresa e alterada sua denominação mercadológica para ZPE CEARÁ, a fim de dotá-la de identidade comercial mais atrativa para o investidor e o mercado.

A seguir, serão apresentadas as sínteses das respostas das entrevistas realizadas com três executivos ( $A, B$ e $C$ ) da gestão superior da EMAZP/ZPE CEARÁ, os quais atuaram, não concomitantemente, desde sua constituição.

\subsection{Síntese das respostas dos entrevistados}

Primeiramente, o executivo A mencionou que o momento inicial referente às ZPE ocorreu nos anos 1980, no governo de José Sarney, então Presidente da República, após retorno de viagem à Coreia do Sul, e que depois foi legalizado em 2007, no governo do Presidente Lula, sob o contexto de forças contrárias oriundas da região Sudeste, pois se tratava de um modelo que buscava descentralizar a produção industrial do país.

Depois, o executivo A registra que o modelo de ZPE adotado no Brasil é baseado no modelo asiático, com incentivos fiscais, delimitação física de área, definição de empresa responsável pela administração da área, rígido controle de acesso e controle aduaneiro.

Assim a ZPE do Pecém foi instalada, e sua história se confunde com a da empresa ZPE CEARÁ, de acordo com o executivo $A$, que informou que o momento inicial ocorreu em dezembro de 2010, quando a empresa foi constituída, em um contexto onde investidores coreanos se associaram a brasileiros para implantar a CSP. Além disso, o executivo A registrou que o grande diferencial do modelo, baseado no asiático, é a segurança jurídica para o investidor internacional, baseada na Lei $n^{\circ}$ $11.508 / 2007$.

$O$ executivo $A$ registrou ainda que a experiência de implantação da empresa ZPE CEARÁ foi muito rica, considerando a urgência para adoção de medidas que tornassem rápida a execução do cronograma de implantação da ZPE do Pecém e da própria empresa, inclusive por interesse dos investidores coreanos, sócios da CSP.

Isso implicou o estabelecimento de legislação estadual com o objetivo de definir os parâmetros da relação entre o governo, por meio da ZPE CEARÁ, e a CSP, pela qual, de acordo com o executivo A:

[...] um dos itens é o de empreender esforços no sentido de implantar a Zona de Processamento de Exportação [...] e a solução foi que a CSP fizesse a estrutura da ZPE para que aí o governo administrasse com sua estrutura organizacional de pessoal e bancasse essa operação. Mas as edificações, a obra, digamos, civil, seria feita pela Siderúrgica. Foi o modelo encontrado para conseguir atender essa demanda.

[...]

Hoje a ZPE é administrada totalmente pelo governo do estado pela empresa ZPE CEARÁ, com toda a equipe e tudo, mas as edificações e a estrutura física foram feitas pela empresa [investidora], e por isso foi feito em prazo recorde.

Com relação ao processo de alfandegamento, o executivo A registrou que existe um roteiro (passo a passo) a ser cumprido junto da RFB, abrangendo entrega de documentação da empresa administradora, da indústria que está se instalando, termos de referência dos equipamentos e sistemas informatizados a serem adquiridos e instalados e 
outros elementos que são protocolados e, após devidamente conferidos, permitem o agendamento da vistoria.

Quanto ao alfandegamento da ZPE do Pecém, a empresa ZPE CEARÁ adotou medidas em articulação estreita com as autoridades fiscais e aduaneiras de modo a viabilizar o mais rapidamente possível a obtenção dessa autorização, conforme declarou o executivo A:

Foi um trabalho feito com vários parceiros: o governo do estado, representado pela ZPE, a Receita Federal, direto aqui com a Superintendência Regional e a CSP, que desde o primeiro momento participou disso, pois tinha interesse direto então tinha representantes dos três e também o acompanhamento de Brasília através do CZPE [...] também com muito interesse aqui no projeto então periodicamente vinha, então foi um trabalho que a gente diz que foi feito a quatro mãos.

Com efeito, o executivo A acrescentou que essa articulação com a Comissão de Alfandegamento permitiu a realização de "vistorias que não foram formais", que contribuíram para que a vistoria definitiva, agendada para o final de fevereiro, viabilizasse a autorização para o funcionamento da ZPE do Pecém em 15 de março de 2013, e com isso a entrada em operação da empresa ZPE CEARÁ em meados de abril de 2013.

As pequenas pendências que tiveram não foram consideradas impeditivas e já foram inclusive corrigidas e supridas. Então nós, a partir do dia 15 de março, com o alfandegamento, já passamos a ser considerados operacionais e aí começamos uma operação piloto. Uma operação assim, corrigindo... como um soft open, quer dizer, começamos realmente a ter ritmo gradativamente. Eu acho que a operação de fato, mesmo, iniciou-se em abril, e maio foi quando a gente começou a ganhar ritmo porque depois de alfandegar nós passamos em torno de uns 60 dias e tiveram vezes que paramos a operação por uma semana para corrigirmos problemas no sistema. Esse foi o nosso maior gargalo.

De acordo com o executivo A, depois de vencido esse problema, a operação iniciou de fato, com a movimentação de cerca de 1.000 toneladas por dia, incluindo máquinas, equipamentos e insumos utilizados no processo de construção da CSP, movimentando atualmente cerca de 2.000 toneladas de materiais por dia.

Outro ponto importante, de acordo com o executivo A, foi o relacionamento de negócios entre as partes. A percepção inicial era de que seria uma espécie de condomínio, mas como não havia referências sobre esse relacionamento a busca na legislação acabou por descartar essa hipótese. Celebrou-se, então, um contrato pelo qual a ZPE CEARÁ é remunerada pela prestação de serviços à CSP.

Resumindo, o executivo A indicou como condições facilitadoras do processo de implantação da ZPE CEARÁ: associação entre investidores coreanos e brasileiros para implantação da CSP; segurança jurídica proporcionada por uma lei específica (Lei $n^{\circ}$ 11.508); alteração de legislação estadual para permitir que a CSP construísse as instalações físicas para funcionamento administrativo da ZPE CEARÁ; articulação da ZPE CEARÁ com a RFB e com o CZPE para rápida obtenção do alfandegamento da ZPE do Pecém e formalização da relação contratual de prestação de serviços entre a ZPE CEARÁ e a CSP.

Contrariamente, em síntese, foram indicados pelo executivo A os seguintes aspectos limitadores ao processo de implantação da ZPE CEARÁ: forças econômicas e políticas contrárias ao modelo ZPE, oriundas da região Sudeste; requisitos normativos e documentais a serem cumpridos para obtenção do alfandegamento da ZPE do Pecém e problemas nos sistemas informatizados de suporte operacional no início da fase de operações da ZPE CEARÁ.

O segundo entrevistado foi o executivo $B$, que elencou as seguintes principais condições 
facilitadoras do processo de implantação da empresa: vontade política do governo do estado do Ceará; celebração de protocolo de investimento com a empresa CSP; apoio da equipe da RFB, no Ceará (RFB-CE) e o apoio do Ministério do Desenvolvimento, Indústria e Comércio Exterior (MDIC), por meio da Secretaria Executiva do CZPE. Nesse contexto, destaca-se a fala do executivo $B$ relativa à vontade política do governo do estado do Ceará:

Eu acho que o grande diferencial da ZPE do estado do Ceará foi a vontade política. Porque ZPE, na verdade, era um tema muito novo, era um tema que ainda falta uma legislação bem específica de alguns trâmites... então... sem a vontade política, sem o interesse, [...] e sem o governo acreditar que isso pode ser sim uma ferramenta de atração de investimentos que pode fazer a diferença no desenvolvimento de um estado, nenhuma ZPE acontece.

O executivo $B$ também esclareceu que as circunstâncias para implantação de qualquer ZPE, no Brasil, colocam um dilema decisório para os governantes públicos quanto ao que fazer primeiro: investir na implantação de uma ZPE e na empresa que a administrará ou atrair investimentos empresariais para em seguida providenciar a implantação da ZPE e de sua administradora.

$\mathrm{Na}$ opinião do executivo $\mathrm{B}$, esse dilema foi diminuído no Ceará porque já havia sido celebrada uma parceria com a CSP, como indica sua opinião:

Na verdade, no estado do Ceará foi totalmente diferente porque a Siderúrgica já tinha sinalizado o interesse em se instalar no estado do Ceará [...] já tinha termo de compromisso, ratificado inclusive por lei, entre o governo do estado e a Siderúrgica, então esse protocolo de intenções, esse memorando de entendimentos demonstrou certa segurança para o estado poder realmente fazer os investimentos na área da ZPE.
O executivo B comentou ainda que o apoio da equipe da RFB-CE foi um fator importante para a implantação da área da ZPE e em consequência da própria empresa, conforme mencionado:

Aqui no estado do Ceará outro diferencial foi realmente a aproximação com a Receita Federal. A Receita Federal ficou próxima do alfandegamento. Contribuiu muito. A gente sabia que tinham situações que era impossível alfandegar, mas mesmo assim ela foi fazer vistoria pra ver se estava tudo andando de acordo com o estabelecido. Assim, ela foi orientando um pouco essa questão de como a gente pode fazer o alfandegamento, o que anda faltando, o que é imprescindível, e isso ajudou muito. [...] Na verdade eu digo que a Receita Federal foi fundamental no alfandegamento.

A propósito desse comentário, registra-se o fato de que o aspecto facilitador citado pelo entrevistado referente ao apoio da RFB-CE está relacionado comumente ao processo de implantação da área da ZPE e da própria empresa ZPE CEARÁ.

$O$ apoio do MDIC, através do CZPE, também foi fundamental, segundo o executivo $B$ :

Eles vinham com frequência para cá, com frequência, e sempre se colocaram disponíveis. Então, em muitas situações eles tiveram que servir como mediadores com a Receita Federal e com o próprio governo federal, então, assim, eles foram sensacionais em todos os momentos. [...] O trabalho do MDIC também foi imprescindível. Eu digo pra você que sem o MDIC e sem a Receita Federal do Ceará, isso aqui, isso aqui não existiria.

Já em relação aos aspectos limitadores do processo de implantação da empresa ZPE CEARÁ, o executivo $B$ ressaltou o cumprimento das exigências legais e normativas e a velocidade da execução dos processos organizacionais na "máquina pública". 
Nesse sentido, em relação ao cumprimento das exigências legais e normativas, o executivo B mencionou que uma das partes mais difíceis é passar pela avaliação da Receita Federal e cumprir todos os requisitos legais para alfandegamento.

A propósito desse registro, destaca-se o entendimento de que a limitação comentada sobre o cumprimento das exigências legais e normativas se refere de forma comum ao processo de implantação da área da ZPE e da própria empresa ZPE CEARÁ, pois a empresa, que é responsável pela gestão da área, enfrenta as mesmas limitações correspondentes à área.

Quanto à velocidade da execução dos processos organizacionais na "máquina pública", o executivo B mencionou que as coisas demoram a acontecer, porque as exigências legais demandam muito mais tempo do que o ideal, mas que não houve dificuldade dentro do próprio governo do estado em conseguir fazer com que as necessidades da constituição da ZPE fossem cumpridas.

O executivo $C$, terceiro entrevistado, referiu-se inicialmente aos aspectos limitadores do processo de implantação da empresa, preferindo denominá -los de desafios. O primeiro desafio mencionado foi o relativo ao fato de o projeto ser novo e com isso acarretar uma série de consequências:

É um desafio muito grande porque você tem um projeto novo em todos os sentidos e todas as suas dimensões. É um projeto novo enquanto administradora, é um projeto novo para as empresas instaladas, é um projeto novo para os governos que estão instalando ZPE no Brasil, em que pese que a nossa do Ceará é a primeira em operação, alfandegada e em operação no país, e nova também até para a gestão federal, que é a CZPE, que é o órgão que controla as ZPEs no Brasil.

Outro aspecto levantado pelo executivo C e que pode se caracterizar como limitador de implantação da empresa está relacionado ao tamanho da área de ZPE sob a administração da empresa. Em suas palavras:

A ZPE CEARÁ é diferente em todos os sentidos [...] porque na concepção de ZPE, algumas leis que são formatadas para um controle ou para uma área pequena [...]. Só que a ZPE CEARÁ tem por decreto uma área de 4.271 ha. Eu já tenho alfandegado quase 600 ha de área. Então, para você fazer a gestão e o acompanhamento enquanto eu sou obrigado, pelo meu órgão anuente, e tenho [...] deveres pra cumprir, é tudo muito grande. Ah, eu tenho que monitorar: são 600 ha [...] Eu tenho que prover eficiência logística da empresa instalada, eu tenho uma empresa com um projeto de US\$ 5 bilhões, que é o maior projeto industrial do país em andamento. Então tudo é muito grande aqui. Então realmente o desafio é [... ] de criar eficiência nessa estrutura.

Em relação às condições facilitadoras, o executivo C elencou: a vontade do governo do estado, a parceria com a Receita Federal, a força de um grande projeto, a criação da ZPE já com a empresa em implantação e a rapidez do processo de autorização legal federal e estadual, nos seguintes termos:

[...] o estado e a ZPE do Ceará tiveram alguns fatores pra desenvolver isso de uma forma um pouco mais acelerada. Primeiro: uma vontade muito grande do governo do estado em fazer isso acontecer, porque se você não tiver esfera política engajada na realização do projeto ele obviamente não sai. Você precisa de uma manifestação de interesse e houve. O estado [...] abraçou o projeto.

Teve uma parceria muito grande com a Receita. O que é difícil porque eles têm os controles e nós temos que apresentar algumas obrigatoriedades, mas são parceiros no sentido do que precisa, se realmente quiseram que a coisa aconteça.

Nós tivemos no estado a força de um grande projeto que tinha que ser instalado que é a Companhia Siderúrgica, 
então a coisa acelerou ainda mais [...] eles têm um cronograma que tinha de ser cumprido. Então precisamos começar a obra em tal data. Então a coisa acelerou.

Então você teve uma série de fatores que casaram na mesma linha do tempo pra fazer a coisa acontecer: o decreto saiu em 2010, do estado, o decreto estadual pra implantação, para a autorização da ZPE do Ceará, e a nível Brasil foi em 2007, foi bem rápido, porque o entendimento de ZPE começou em 1988, então você tem aí mais de 25 anos [...] a coisa aconteceu no Brasil em 2007, e em 2010 o estado autorizou a ZPE e em 2013 estava alfandegada e implantada.

Diante de todo o exposto, as sínteses das respostas das entrevistas realizadas com os três executivos da gestão superior da empresa ZPE CEARÁ acerca das condições facilitadoras e dos aspectos limitadores do processo de implantação da companhia podem ser resumidas conforme indicado no Quadro 1.

\section{CONCLUSÃo}

O objetivo geral definido para esta pesquisa foi identificar e caracterizar as condições facilitadoras e os aspectos limitadores do processo de implantação da empresa ZPE CEARÁ, à luz da Visão Baseada nas Instituições.

Considerando o argumento de Peng, Wang e Jian (2008) sobre como a Visão Baseada em Instituição pode orientar a estratégia de internacionalização e determinar o sucesso ou fracasso das empresas, entende-se que os resultados da pesquisa, especialmente as respostas obtidas pela realização de entrevistas junto a executivos que integram ou integraram a gestão superior da empresa ZPE CEARÁ, sintetizadas no Quadro 1, permitem concluir que as condições facilitadoras, especialmente, e os aspectos limitadores desse processo estão relacionados à Visão Baseada nas Instituições.

Assim, considerando as definições de North (1990) sobre as restrições formais e informais (regras do jogo) que caracterizam as instituições de Scott

Quadro 1 - Síntese das respostas das entrevistas realizadas com executivos da ZPE CEARÁ

\begin{tabular}{|c|c|c|}
\hline Entrevistado & Condições facilitadoras & Aspectos limitadores \\
\hline Executivo A & $\begin{array}{l}\text { Associação entre investidores coreanos e brasileiros para } \\
\text { implantação da CSP. } \\
\text { Segurança jurídica proporcionada por uma lei específica (Lei nº } \\
\text { 11.508). } \\
\text { Alteração de legislação estadual para permitir que a CSP } \\
\text { construísse as instalações físicas para o funcionamento } \\
\text { administrativo da ZPE CEARÁ. } \\
\text { Articulação da ZPE CEARÁ com a RFB e com o CZPE para rápida } \\
\text { obtenção do alfandegamento da ZPE do Pecém. } \\
\text { Formalização da relação contratual de prestação de serviços } \\
\text { entre a ZPE CEARÁ e a CSP. }\end{array}$ & $\begin{array}{l}\text { Forças econômicas e políticas contrárias ao } \\
\text { modelo ZPE, oriundas da região Sudeste. } \\
\text { Requisitos normativos e documentais a serem } \\
\text { cumpridos para obtenção do alfandegamento } \\
\text { da ZPE do Pecém. } \\
\text { Problemas nos sistemas informatizados de } \\
\text { suporte operacional no início da fase de } \\
\text { operações da ZPE CEARÁ. }\end{array}$ \\
\hline Executivo B & $\begin{array}{l}\text { Vontade política do governo do estado do Ceará. } \\
\text { Celebração de protocolo de investimento com a empresa } \\
\text { Companhia Siderúrgica do Pecém (CSP). } \\
\text { Apoio da equipe da Receita Federal do Brasil no Ceará (RFB-CE). } \\
\text { Apoio do Ministério do Desenvolvimento, Indústria e Comércio } \\
\text { Exterior (MDIC), por meio da Secretaria Executiva do Conselho } \\
\text { Nacional das Zonas de Processamento de Exportação (CZPE). }\end{array}$ & $\begin{array}{l}\text { Cumprimento das exigências legais e } \\
\text { normativas. } \\
\text { Velocidade da execução dos processos } \\
\text { organizacionais na "máquina pública". }\end{array}$ \\
\hline Executivo $\mathrm{C}$ & $\begin{array}{l}\text { Vontade do governo do estado. } \\
\text { Parceria com a Receita Federal. } \\
\text { Força de um grande projeto (da CSP). } \\
\text { Criação da ZPE já com a empresa em implantação (CSP). } \\
\text { Rapidez do processo de autorização legal federal e estadual. }\end{array}$ & $\begin{array}{l}\text { Natureza inusitada do projeto para todos } \\
\text { os agentes envolvidos (governo, empresa } \\
\text { administradora da ZPE e investidores). } \\
\text { Tamanho da área de ZPE sob a administração } \\
\text { da ZPE CEARÁ. }\end{array}$ \\
\hline
\end{tabular}

Fonte: Elaborado pelos autores. 
(2008) acerca das estruturas e atividades regulatórias, normativas e cognitivas que dão o contorno das instituições, e de Peng (2008), tratando do poder coercitivo dos governos (por meio de leis e regulamentos) como essência do pilar institucional regulatório e da cultura como base das instituições informais e do pilar normativo e cognitivo das instituições, podese observar que das 14 condições facilitadoras para o processo de implantação da ZPE CEARÁ indicadas sinteticamente no Quadro 1, apenas duas (força de um grande projeto e criação da ZPE já com a empresa em implantação, ambas da (SP) não encontram suporte nessas definições, e sim na RBV.

Na sequência, examinando os sete aspectos limitadores do processo de implantação da ZPE CEARÁ, também sinteticamente relacionados no Quadro 1, à luz dos mesmos autores, verifica-se que três aspectos limitadores (problemas nos sistemas informatizados de suporte operacional no início da fase de operações da empresa, natureza inusitada do projeto para todos os agentes envolvidos - governo, empresa administradora da ZPE e investidores e tamanho da área sob a administração da ZPE (EARÁ) estão suportados pela RBV.

Diante do exposto, considera-se que o problema desta pesquisa - como se deu o processo de implantação da empresa ZPE CEARÁ enquanto agente institucional para implementação de políticas públicas de comércio exterior? - pode ser respondido pela conclusão de que fatores relacionados à Visão Baseada nas Instituições influenciaram o processo de implantação da empresa ZPE CEARÁ, especialmente no que se refere às correspondentes condições facilitadoras.

Assim, entende-se que o objetivo desta pesquisa foi atendido. Entretanto, é importante destacar sua limitação, que é que por se tratar de uma pesquisa qualitativa, seus resultados não podem ser generalizados.

Finalmente, nota-se a concepção de que novos estudos podem ser realizados em relação ao processo de implantação de outras ZPEs, inclusive com a finalidade de realizar comparações com a implementação da ZPE do Ceará, como forma de contribuir para análise da eficácia dessa política pública de comércio exterior.

\section{AGRADECIMENTOS}

Agradecemos o inestimável apoio da CAPES, da UNIFOR e da Controladoria e Ouvidoria Geral do Estado do Ceará. Agradecemos também à empresa ZPE CEARÁ e aos seus executivos e ex-executivos pela possibilidade de realização da pesquisa. Ainda estendemos nossos agradecimentos aos revisores anônimos do XVII SEMEAD, que muito contribuíram para o aperfeiçoamento deste trabalho.

\section{REFERÉNCIAS}

ABRAZPE. Associação Brasileira de Zonas de Processamento e Exportação. Victor Samuel Ponte. Zona de processamento de exportação do Pecém ZPE CEARÁ. Disponível em: <http://www.fiec.org. br/palestras/negocios_internacionais/ZPE170111/ ZPE170111.pdf>. Acesso em: 8 dez. 2013.

ACIOlY, L.; ALVES, M. A. S.; LEÃO, R. P. F. Nota técnica: a internacionalização das empresas chinesas. IPEA, 2009. Disponível em: <http://www.ipea. gov.br/agencia/images/stories/PDFs/2009_nt01_maio_ deint.pdf>. Acesso em: 20 nov. 2013.

ACIOLY, L.; SCHATZMANN, S. Políticas de promoção e apoio à internacionalização de Empresas. In: CAMEX. Termo de Referência: internacionalização de empresas brasileiras. 2009. Disponível em: <http://www.mdic.gov.br/arquivos/ dwnl_1260377495.pdf>. Acesso em: 20 nov. 2013. 


\section{REFERÊNCIAS}

BEUREN, I. M. (Org.). Como elaborar trabalhos monográficos em contabilidade: teoria e prática. São Paulo: Atlas, 2004.

BRASIL. Decreto Federal, de 16 de junho de 2010. Cria a Zona de Processamento de Exportação ZPE de Pecém, no Município de São Gonçalo do Amarante, no Estado do Ceará. Brasília, DF, 16 jul. 2010. Disponível em: <http://www.planalto.gov. br/ccivil_03/_ato2007-2010/2010/Dnn/Dnn12646. htm>. Acesso em: 30 jul. 2014.

Lei $n^{\circ} 11.508$, de 20 de julho de 2007. Dispõe sobre o regime tributário, cambial e administrativo das Zonas de Processamento de Exportação, e dá outras providências. Brasília, 2007. Disponível em: <http://www.planalto.gov.br/ ccivil_03/_ato2007-2010/2007/Lei/L11508.htm>. Acesso em: 30 jul. 2014.

CÂMARA DE COMÉRCIO EXTERIOR (CAMEX). Termo de Referência: internacionalização de empresas brasileiras. 2009. Disponível em: <http:// www.mdic.gov.br/arquivos/dwnl_1260377495. pdf>. Acesso em: 20 nov. 2013.

DELFIM NETTO, A.; BRAGA, H. C. O " $A B C$ " das zonas de processamento de exportação (ZPEs). 2006. Disponível em: <http://www.abrazpe.org. br/index.php/download/category/29-nacionais> Acesso em: 27 nov. 2014.

EMPRESA ADMINISTRADORA DA ZONA DE PROCESSAMENTO DE EXPORTAÇÃO DE PECÉM S/A. Relatório de desempenho de gestão. 2011. Não publicado.

. Relatório de desempenho de gestão. 2012.

Não publicado.
Relatório de desempenho de gestão. 2013. Não publicado.

LEUNG, K. et al. Culture and international business: recent advances and their implications for future research. Journal of International Business Studies, v. 36, n. 4, p. 357-378, 2005.

MINISTÉRIO DO DESENVOLVIMENTO, INDÚSTRIA E COMÉRCIO EXTERIOR. Regime brasileiro das zonas de processamento de exportação - ZPE: informações básicas. 2013a. Disponível em:<http://www. desenvolvimento.gov.br/arquivos/dwnl_1380118114. pdf>. Acesso em: 22 out. 2013.

Zonas de processamento de exportação: informações básicas e legislação. 2013b. Disponível em: <http://www.desenvolvimento.gov.br/arquivos/ dwnl_1374586708.pdf>, acesso em: 22 out 2013.

NORTH, D. C. Institutions, institutional change and economic performance. Cambridge: Cambridge University Press, 1990.

PENG, M. W. Estratégia global. São Paulo: Thomson Learning, 2008.

. País está movendo o mundo, mas pode investir muito mais. Brasil Econômico, São Paulo, p. 8-9, 30 jun. 2010.

PENG, M. W.; WANG, D. Y. L.; JIANG, Y. An institutionbased view of international business strategy: a focus on emerging economies. Journal of International Business Studies, n. 39, p. 920-936, 2008.

REDDING, G. The thick description and comparison of societal systems of capitalism. Journal of International Business Studies, v. 36, n. 2, p. 123-155, 2005. 


\section{REFERÊNCIAS}

RUDIO, F. V. Introdução ao projeto de pesquisa. Petrópolis: Vozes, 1995.

SANTOS JUNIOR, R. ZPES: Zonas de Processamento de Exportação - de Shanon a Parnahyba. Parnaíba: Sieart, 2013.

SCOTT, W. R. Institutions and organizations: ideas and interests. 3. ed. Califórnia: Sage Publications, 2008.
VERGARA, S. C. Projetos e relatórios de pesquisa em administração. São Paulo: Atlas, 1997.

YIN, R. K. Estudo de caso: planejamento e métodos. 3. ed. Porto Alegre: Bookman, 2005. 